\title{
The Burdens of Survivorship: An Approach to Thinking about Long-Term Outcomes after Critical Illness
}

\author{
Theodore J. Iwashyna, M.D., Ph.D. 1,2,3 Giora Netzer, M.D., M.S.C.E. ${ }^{4,5}$
}

${ }^{1}$ Department of Medicine, University of Michigan, Ann Arbor, Michigan

2 Institute for Social Research, Ann Arbor, Michigan

${ }^{3}$ VA Center for Clinical Management Research, Ann Arbor, Michigan

${ }^{4}$ Division of Pulmonary and Critical Care Medicine, University of Maryland, Baltimore, Maryland

${ }^{5}$ Department of Epidemiology and Public Health, University of Maryland, Baltimore, Maryland
Address for correspondence and reprint requests Theodore J. Iwashyna, M.D., Ph.D., $3 a 23300$ NIB, SPC 5419, 300 North Ingalls, Ann Arbor, MI 48109 (e-mail: tiwashyn@umich.edu).

Semin Respir Crit Care Med 2012;33:327-338.

\begin{abstract}
Internationally accepted approaches to the study of functioning and disability can inform critical care practitioners and scholars in their study of functional limitations, disability, and quality of life after critical illness and intensive care. Therefore this article provides an introduction to the World Health Organization's International Classification of Functioning, Disability and Health (ICF). The Institute of Medicine has also recommended this approach for the study of disability. This conceptual framework divides potential problems as follows: problems in body structure and tissue, limitations in activity (i.e., functional limitations as assessed in standardized environments), and restrictions in participation (i.e., the inability to fulfill a social role). The ICF draws

Keywords

- critical illness

- post-intensive care syndrome (PICS)

- survivorship

- disability

- quality of life attention to effect modifiers that can prevent problems at one level from progressing (or conversely can hasten their progression) to profound decrements in a patient's quality of life. It is particularly relevant for studies of long-term outcomes after critical illness and post-intensive care syndrome (PICS). This article provides a discussion of the ICF specific to the intensive care unit and the disablement process, with particular attention to new opportunities for intervention and their implications for cost and quality of life.
\end{abstract}

The study of long-term outcomes of critical illness can be improved by placing the work and the data within the context of a broader research on disability. The National Heart Lung and Blood Institute of the National Institutes of Health recently published a position statement calling for a standardized approach to outcomes assessment, emphasizing the need for cross-study comparability. ${ }^{1}$ This article introduces a framework for defining and studying disability using the World Health Organization's (WHO) International Classification of Functioning, Disability and Health (ICF). ${ }^{2}$ The ICF builds on years of rigorous social, scientific, and epidemio-

Issue Theme Intersection of Outcomes, Ethics, and Economics in Critical Care; Guest Editors, Constantine A. Manthous, M.D., F.A.C.P., F.C.C.P., Douglas B. White, M.D., M.A.S., and Shannon S. Carson,

M.D. logical study ${ }^{3,4}$ and has been recommended by the US Institute of Medicine as a key conceptual framework. ${ }^{5,6}$ Thinking about long-term outcomes in the context of the ICF is an opportunity to reconcile disparate findings and, more importantly, to consider new and unexplored interventions that may provide sustained improvements in the lives of survivors of critical illness.

The ICF divides the sequelae of acute illness into three nested categories: damage to body structures, limitations in activity, and restrictions in participation in social roles. This article applies this approach to critical illness survivorship

Published by Thieme Medical Publishers, Dol http://dx.doi.org/ Inc., 333 Seventh Avenue, New York, NY 10.1055/s-0032-1321982. 10001 , USA. ISSN 1069-3424.

Tel: +1(212) 584-4662. 
and follows recent scholars in adding a fourth category, quality of life. These categories can also be organized into a progression known as the disablement process, providing an approach to thinking about how tissue damage may lead to impaired quality of life. ${ }^{3}$ Equally valuable, the ICF provides a framework for studying the social, psychological, and health care factors that act as effect modifiers, preventing or exacerbating progression of the disablement process in an individual patient. Each of these effect modifiers provides an opportunity for clinicians to help their patients.

In introducing the ICF, this article first explains the WHO classification system and the disablement process as it applies to critical illness. This is followed by a discussion of how nonmedical factors modify the progression through the disablement process, creating new measurement variables for researchers and new opportunities for clinicians and clinical researchers to develop tools for their armamentarium. Third, the text identifies actions in the intensive care unit (ICU) that prevent progression through the disablement process. Fourth, the discussion turns to the relationship between post-ICU functioning and health care costs. The article concludes by briefly discussing the implications of this approach for clinicians and researchers and introducing the accompanying two articles (Kress and Herridge, and Hopkins and Girard).

\section{Basic Conceptual Model: Distinguishing Impairment, Limitations, Restrictions, and Quality of Life}

In pulmonary clinic, fellows are taught that a patient's shortness of breath is not fully determined by the forced expiratory volume in 1 second $\left(\mathrm{FEV}_{1}\right)$. The distance covered during a 6-minute walk is not simply proportional to the $\mathrm{FEV}_{1}$; it is dependent on a complex interaction of extrapulmonary factors. Damage from an illness may occur at several levels that build on each other without manifesting a 1-to-1 correspondence. This insight forms the basis of the WHO ICF, which itself builds on seminal work by Verbrugge and Jette on the disablement process. $^{3}$

The basic conceptual model is presented in - Fig. 1. Patients may become critically ill in a body already suffering chronic problems. Critical illness may cause impairmentsthat is, the fundamental organ failures with which clinicians struggle daily. These impairments occur at the level of specific tissue damage and may be transient or permanent. These impairments may then cause activity limitations in functional activities. Limitations in physical and cognitive abilities may, in turn, lead to the restrictions in participation in social rolesthat is, to disability. The ICF draws a distinction between what a person can do in a standardized testing environment (limitations) and what can be done in the patient's usual environment (disability). The perception of such disability and pursuant adaptation may impair quality of life. Consider the example of Mr. Jones, whose ICU-acquired weakness leads to atrophy of the quadriceps (an impairment), resulting in sitto-stand inability (an activity limitation). Mr. Jones previously lived in a split-level ranch house with a master bedroom on the second floor. He can no longer climb the stairs to his

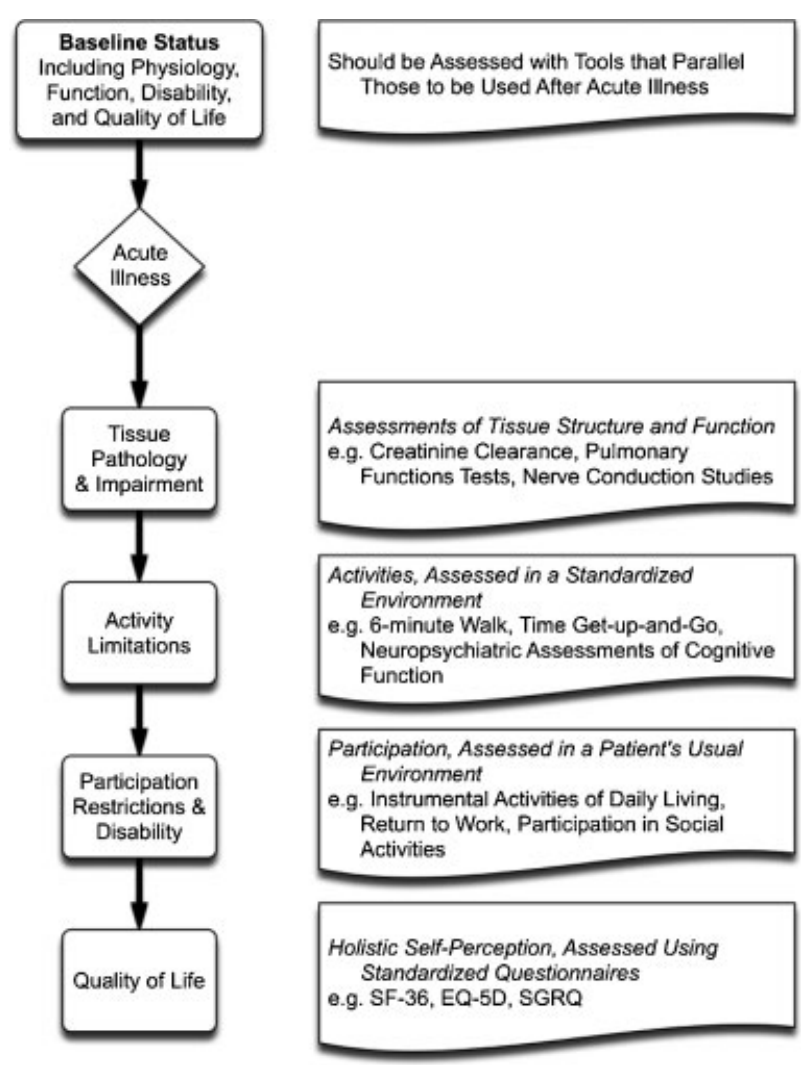

Figure 1 A conceptual model for studying long-term outcomes after critical illness, rooted in the International Classification of Functioning, Disease and Health.

bedroom (a disability) and is unable to return home. This makes him profoundly unhappy (reduced quality of life).

The fundamental insight of contemporary disability research is the recognition that impairment, limitation, restriction, and quality of life are distinct aspects of response to a given illness. Different aspects require diverse approaches to assessment and will be differentially influenced by potential interventions. To grasp this model is to understand that a set of steps cumulates into a process eventually resulting in disablement. Disability is not foreordained but builds through layers. Continuing our example, whether Mr. Jones's atrophied quadriceps preclude his ability to return home-that is, the extent to which his ICU-acquired weakness will result in diminished quality of life-may depend on therapies he received in the hospital (e.g., neuromuscular blockade), whether he received early mobilization, and the resultant strength of his other muscles and their ability to compensate; his ability and willingness to learn new approaches to mobility; the design of his home and whether he can afford a stairclimber; and the availability and strength of caregivers at his home.

Intensivists are familiar with the measurement of tissue impairment after critical illness. Clinical assessment and research measurement of this aspect of survivorship typically requires direct examination of the patient's body, often with tissue sampling or noninvasive imaging. Examples include computed tomographic (CT) scans, creatinine clearance, and 
muscle biopsies-the sorts of bedside tests familiar to clinical practitioners.

Assessments in a standardized environment are used to determine whether a patient has limitations in abilities. Cognitive assessments of executive function and memory tap this aspect of the disablement process. Motor function tests for limitation include the timed up-and-go and swallowing tests. There has been substantial effort in geriatrics and kinesiology research in this domain, with the development of strong measurement tools and a resultant deep understanding of conditions such as hip fracture and stroke. Limitations are distinguished from impairments by the focus on activity at a level recognizable to the patient.

Crucially, the linkage between tissue injury and limitation in abilities is often variable. Clinicians understand that a low cardiac ejection fraction or deconditioning may correspond to a wide range of 6 -minute walk times, ${ }^{7,8}$ and that the extent of ischemic damage on a head CT is only one predictor of functional deficits after stroke. ${ }^{9-11}$ The mechanisms that drive this heterogeneity are a potentially rich area of study. For example, a recent review of stroke rehabilitation emphasized that there appears to be little recovery of damaged parts of the brain per se; however, the remarkable plasticity of the brain allows substantial compensation at the level of functional limitations rather than repair of the brain itself. ${ }^{12}$ The variability between tissue damage and basic function points to important opportunities to improve function, even after tissue damage has been completed.

Disability is defined by the restrictions in participation through a given social role. The degree of disability depends on the complex interplay between the patient's functional limitations, the expectations placed upon them, and the social and technological environment in which this occurs. To give an example, many community-dwelling adults have poor distance vision. Without corrective devices, this would cause substantial disability, precluding them from driving or even enjoying a movie. With glasses, these individuals have no social disability despite precisely the same limitations in their ability. More generally, this distinction between functional limitations and disability crystallizes a common clinical insight among critical care physicians: that there are particular patients for whom seemingly innocuous functional deficits have a disproportionately negative impact on their lives. These patients could be the former athlete whose modestly diminished diffusing capacity, while still "in the normal range," means that he can no longer compete, or the former executive for whom a small diminishment in the ability to concentrate has meant the loss of her once-prosperous small business. For these survivors, their social roles demand higher degrees of function, resulting in disability for them but perhaps not for others. Verbrugge and colleagues emphasized that, while functional limitations may be set by the biology of illness, the extent of social disability is fundamentally dependent onand can be improved by-the social environment in which a patient lives. ${ }^{3,13}$ Common measures of disability include assessments of the ability to return to work and of independence in performing activities of daily living and instrumental activities of daily living.
Quality of life is intended as a holistic measure of the extent to which a patient is satisfied with his or her life. Its measurement has deep roots in economics. For many clinical applications, scientists prefer the concept of "health-related quality of life," which has been defined as "the relative desirability of measured or estimated health states." ${ }^{14}$ In principle, this allows rational and humanistic trade-offs, incorporating the choice by some that they would rather live for less time at a higher level of capacity. Health-related quality of life, particularly as embodied in the quality-adjusted life year, has been accepted as perhaps the dominant outcome for cost-effectiveness analysis in medicine. The assessment of quality of life requires a precise and structured approach; the optimal measurement is still debated and may hide contentious decisions about precisely whose point of view should be valued, but this discussion is outside the scope of this article. ${ }^{14-17}$

In summary, the ICF serves as a conceptual model for increasing our understanding of critical care survivorship. This model organizes the condition of survivors in terms of distinct phases, which can be understood as a disablement process: an acute injury modifying a baseline level, causing a pathology of injury that leads to tissue impairment, leading to functional activity limitations, which may lead to disability in the participation in social roles, and which may be associated with changes in quality of life. Such an approach is rooted in decades of geriatric and sociological study. Although the ICF and the theory of the disablement process continue as subjects of discussion and refinement, ${ }^{18-20}$ they organize the facets of survivorship in ways allowing potentially productive analogies with long-standing work in related fields, such as geriatrics and stroke rehabilitation. They clarify potential sources of variability in the process and suggest ways this variability could be exploited to develop new interventions. This approach also offers a natural way to understand the complex process of patient care that may have important effects on the experience of survivorship.

\section{Effect Modification by Social and Psychological Factors during Disablement}

A key insight of work on the disablement process-and the conceptual underpinning of the WHO ICF-is the recognition that the process by which functional limitations become restrictions on social participation is dependent on the social environment. This fact complicates the lives of ICU-based scientists because it requires them to conceptualize and measure aspects of patients' lives outside of their usual practice. But it can expand the armamentarium of clinicians committed to improving patients' lives.

In the realm of critical illness, there has been relatively little scientific study of the ways in which social and psychological factors explain variation in patients' progression through the disablement process. Thus this section draws on related literature to briefly sketch certain effect modifiers and the steps at which they may act. - Figure $\mathbf{2}$ presents an overview.

There is reason to suspect effect modification even at the linkage between acute illness and tissue impairment. For 


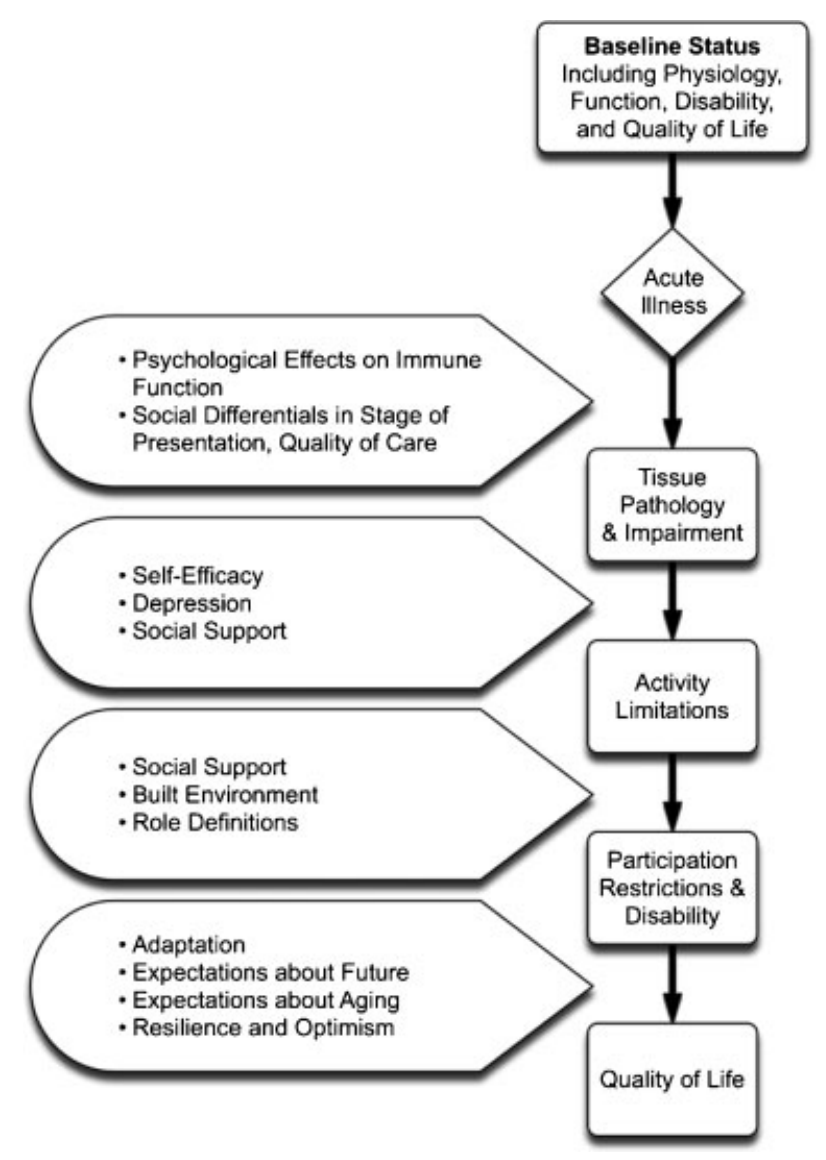

Figure 2 The social environment and psychological makeup are crucial effect modifiers for progression through the disablement process.

example, there may be direct immunomodulatory effects of both psychological states (such as depression) and social support and social networks. ${ }^{21}$ Patients with a more privileged social position (eg, race, greater wealth and education) may be more likely to present to the health care system earlier in the course of their disease. They may go to hospitals that provide better care ${ }^{22,23}$; certainly this is true on a global scale. Persistent and frustrating evidence suggests that differential care exists even within the same hospital, ${ }^{24,25}$ which translates into social differentials in degrees of tissue impairment from the same apparent critical illness. As shown in the next section, hospitals may intervene during every step of the disablement process; therefore, social differentials in the choice of hospital may ramify at each level of that process.

Psychological factors may be particularly relevant in modifying the extent to which tissue impairment leads to functional limitations. Self-efficacy and depression have been associated with reduced physical activity and participation in rehabilitation. ${ }^{26}$ Social support, here as at nearly every step, appears to be crucial. This is particularly concerning, given recent research showing that spouses and informal caregivers of the critically ill suffer depression and posttraumatic stress and its symptoms. ${ }^{27}$ Directed support of family members during critical care ${ }^{28,29}$ may yield important downstream benefits for patients, although this needs to be tested.
Because restrictions in social roles are defined in terms of the social environment, it is not surprising that there are many potential modifiers of the relationship between functional limitations (assessed in a standardized environment) and restrictions and disability (assessed in the patient's usual social context). A few broad domains stand out: (1) social support and social networks, (2) the built environment, and (3) role definitions.

1. With regard to social support, studies have shown that caregivers can buffer survivors from the impact of their limitations, serving as social assistive devices. ${ }^{30}$ For example, caregivers can prevent patients from being moved to a nursing home (an extreme form of social disability) for patients with well-characterized dementia. ${ }^{31}$ To our knowledge, equivalent data have not been collected after critical illness.

2. The built environment comprises "all buildings, spaces and products that are created or modified by people." 32 This architecture and the design of the spaces of our lives may have a profound impact on a patient's experience of them. This may be most familiar to many clinicians from ways in which grab bars and other bathroom modifications may allow patients to toilet themselves in an appropriate bathroom, despite the inability to do so in a conventional residential bathroom. ${ }^{33-35}$ The Americans with Disability Act has led to the redesign of some public spaces to increase mobility and reduce disability, although barriers remain, particularly in private homes. ${ }^{36,37}$

An elegant study utilized self-reported measures of lower limb function and mobility disability and characterized street conditions outside of respondents' homes. ${ }^{38}$ The investigators found that rates of mobility disability were much higher among those with lower body impairment who lived in an area with fair or poor streets compared with those living on well-maintained streets. This disparity persisted after extensive controls for potential confounders. That is, the relationship between functional limitations and social disability varies as a function of the local built environment, reinforcing the findings of several studies that used less granular data. ${ }^{32,39,40}$ This suggests that the home and neighborhood environments where our patients live may be important determinants of the degree of social disability-but also that there might be powerful effects from modifications of those environments or the patient's ability to interact with them.

3. Role definitions are the set of social expectations and demands placed on us in each of the social roles we fill. In some cases, those role definitions may be binding, and any diminishment in function will result in the inability to fulfill the role. In other cases, there may be more slack, or even opportunities to redefine the role so that once seemingly essential characteristics are no longer so. At a global level, male gender was once considered an essential characteristic for a fire fighter or a law enforcement officer. At a local level, ramps and curb cuts mean that ambulation is no longer a requirement for participation in many aspects of urban life for otherwise mobility-impaired 
people, ranging from those in wheelchairs to parents with strollers. At an individual level, a surgeon with new leftsided hemiparesis that precludes him or her from operating may redefine the job role by using analytic skills to mentor and teach.

In understanding survivorship, it is essential to understand that not all patients will evaluate the same degree of functional limitations and social disability equivalently in terms of their effect on their health-related quality of life. Psychological adaptation and other resources play a crucial role in mediating these relationships. ${ }^{41}$ Furthermore, such adaptations can lead to substantial differences in the quality of life impact of a given degree of activity limitation. To highlight these challenges, consider an astute study by Smith and colleagues. ${ }^{42}$ They identified 71 patients who had recently undergone either temporary or permanent colostomy or ileostomy at a major tertiary care center. At 1 week postdischarge, quality of life scores were indistinguishable between the groups. Over the next 6 months, the permanent ostomy group had steady and clinically and statistically significant improvements in their quality of life. In contrast, the temporary ostomy group had persistently low quality of life that did not improve. The authors posited that when patients were hopeful that a given disability was temporary they did not adapt to the situation and thus experienced poor quality of life. When the ostomies were clearly permanent, the patients adapted to the same disability with progressively improving quality of life. This emphasizes the variable, and perhaps unexpected, linkages between the functional limitations, disability, and quality of life of survivors of critical illness. ${ }^{43-45}$ It further highlights that interventions which promote adaptation may offer intriguing benefits.

In sum then, the ICF organizes the potential challenges faced by survivors of critical illness and highlights the flexible interrelationships of those challenges. Social and psychological factors-many open to amelioration-may critically modify the extent to which a given tissue injury leads to social disability. These many effect modifiers suggest that the goal of care may then be to both minimize functional limitation and disability and to maximize the quality of life, but without the expectation that improvements in one will always correspond with improvements in the other.

\section{Health Care as Modifier and as Outcome of the Disablement Process}

A patient's health care needs and utilization have an interactive relationship with the disablement process. On the one hand, an important goal of much care is to prevent or ameliorate disablement. Yet impairments, limitations, and restrictions may also lead to both a greater need for health care and greater use of services. It is useful to consider these separately. Let us first look at the ways in which care during the acute illness can potentially interrupt disablement. We will then consider health care needs and use.

\section{Current ICU Practices That May Influence Survivorship and the Disablement Process}

The traditional view of survivorship is that it is an issue to be addressed after the acute illness is completed. But recent work in mechanically ventilated patients-and current practice with stroke, trauma, and cardiac surgery patientssuggests that targeted care during the acute setting can improve long-term survivorship. Rapid postoperative extubation may speed coronary artery bypass surgery patients off mechanical ventilation in hours after leaving the operating room. ${ }^{46-51}$ Stroke rehabilitation begins in the ICU. ${ }^{52-54}$ In the medical ICU, current excitement focuses on the dramatic gains resulting from rehabilitation during the ICU stay. ${ }^{55-58}$ A host of current practices influence various transitions between the steps of functioning, disability, and quality of life. - Figure 3 provides a comprehensive list; the focus here is on action in the ICU.

Preventing long-term adverse outcomes from critical illness can begin with preventing critical illness. This suggests that existing patient safety efforts to reduce infection ${ }^{59-61}$ and acute lung injury ${ }^{62}$ may have an important role in preventing post-critical illness disability when considered at the population health level.

Much of critical care is devoted to the prevention of tissue damage and organ failure. However, far less attention has been directed toward rigorously evaluating the impact of our

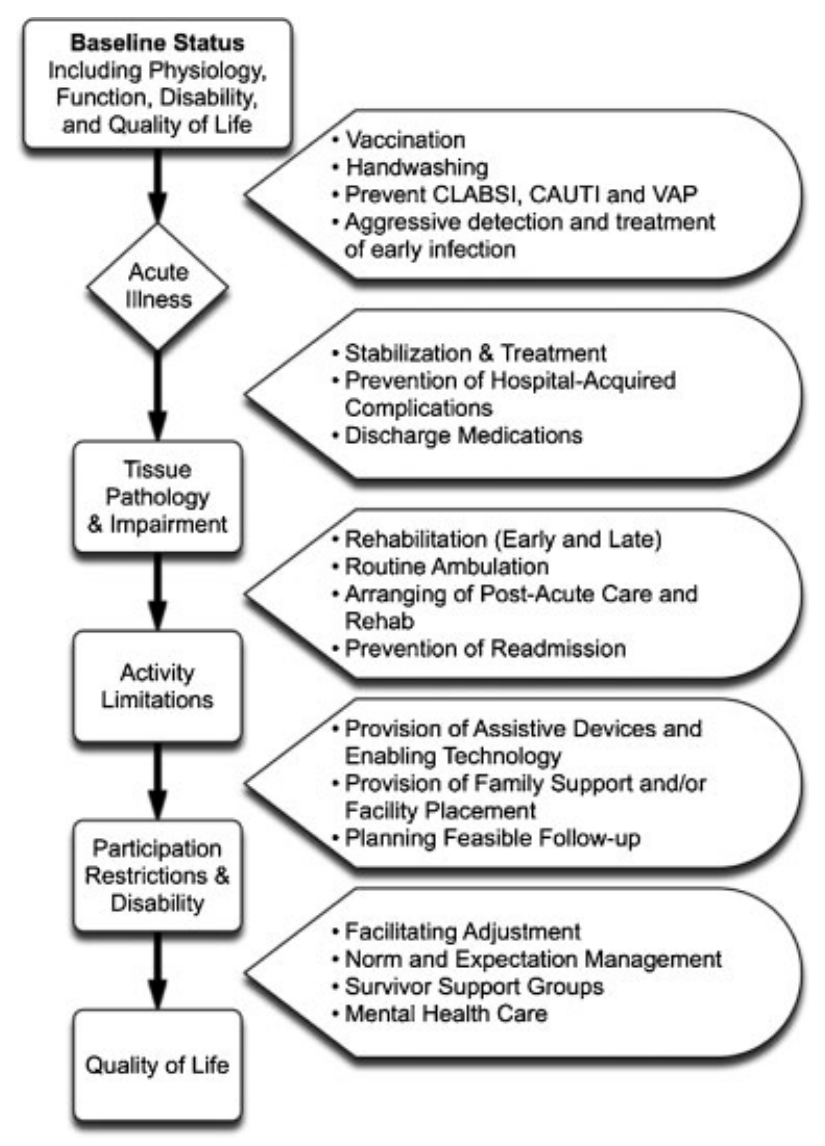

Figure 3 Current routine practices by acute care hospitals that may have effects on the disablement process. 
therapies on long-term outcomes. Fascinating 1-year mortality and cognition data are available for the pairing of a spontaneous awakening trial and spontaneous breath trial, the Awakening and Breathing Controlled $(\mathrm{ABC})$ trial, ${ }^{63}$ and a follow-up evaluated some of the patients in the Fluids and Catheter Treatment Trial (FACTT). ${ }^{64,65}$ But these trials are notable also for how unusual the collection of these outcomes was. Meaningful long-term outcomes are not yet routinely collected in randomized, controlled trials nor required by the Food and Drug Administration for approval. ${ }^{66,67}$ It seems a reasonable extrapolation that other advances in contemporary critical care, such as early goal-directed resuscitation and low tidal volume mechanical ventilation, will also offer benefits in terms of survivorship. But it must be emphasized that there is painfully little proof that these fundamental therapies do improve long-term outcomes. Getting such proof would be of substantial scientific merit ${ }^{66}$ and may help clarify the mechanisms leading to various aspects of survivorship. Particularly, such data might provide insight into the extent to which the general ICU environment (possibly including existing care practices), as opposed to specific pathophysiological pathways, causes the components of disability.

In the ICU, explicit interventions to prevent functional limitations typically rely on physical and occupational therapy. Enacting such therapy broadly requires not only dedicated time with highly skilled therapists but also core nursing tasks, including sedation minimization, that allow patients to engage in as much self-care as possible, and frequent time out of bed. ${ }^{68}$ Hospital variations in physical therapy practices may be marked. ${ }^{69}$ Mobility-related activities have been called the most common "error of omission" by nursing care on general floors, ${ }^{70,71}$ and there are few reasons to think this is better in the ICU. Although there are promising data about new interventions to improve cognition after critical illness ${ }^{72}$ and there is useful evidence from other related fields, ${ }^{12,73-75}$ such interventions are not yet well integrated into ICU care.

Other ICU interventions not directly targeted to improving functional status may also have critical "side-effects" in this step in the disablement process. ${ }^{68}$ The interdependence of sedation, delirium, and patient activity has been increasingly evident since Kress et al's ground-breaking study. ${ }^{76}$ Sedation minimization makes possible active patient participation for many hours a day, from the crucial muscular activity of maintaining posture in a chair to playing video games. ${ }^{77,78}$ Delirium prevention may improve the long-term outcomes of both mortality and cognition. ${ }^{79-81}$ Conversely, other initiatives intended to improve patient safety may have deleterious effects. Inouye and colleagues have pointed out that the labeling of in-hospital falls as never-events may lead instead to immobilization and unnecessary loss of functional capacity. ${ }^{68}$ As we consider the mobilization of hospitalized patients, we should remember that the mortality benefits of paired spontaneous breathing and awakening trials ${ }^{63}$ are comparable to those of low tidal volume ventilation. ${ }^{82}$

It is easy to overlook the potential for ICU-based interventions to prevent given functional limitations from becoming social disability. Occupational therapy (OT) plays a role, teaching patients to compensate for physical limitations to avoid disability. ${ }^{83,84}$ Although their efforts are often overlooked, the trial by Schweickert et al randomized patients to treatment by a physical therapy/occupational therapy (PT/ OT) team, not just PT. ${ }^{58}$ One might speculate that OT care should begin in the ICU, and arranging appropriate care transitions is essential. ${ }^{85}$ It is likely hospitals vary in other processes that effect social disability and quality of life, holding constant functional limitations; identifying these is an important area for our study of long-term outcomes.

Further, it is our suspicion-as of yet unproven-that ICU efforts to support spouses and families may offer substantial possibilities in preventing disability. Spouses have been proven to be a crucial determinant of whether cognitive decline leads to nursing home use. ${ }^{31}$ The health benefits that flow from social support in general, and families in particular, are well documented and appear to be causal, not just associated. ${ }^{30}$ Families provide enormous hours of uncompensated but crucial informal care after many conditions. ${ }^{86-94}$ Yet the families of ICU patients leave our care with substantial burdens, including depression, anxiety, and learned helplessness. ${ }^{28,29,86,95-103}$ As Kress and Herridge suggest in their article in this volume, interventions supporting families during their loved ones' ICU stay could empower these families to provide high-quality, personalized support in the post-ICU period. This "social reserve"-analogous to physiological reserve-may be heedlessly diminished by current ICU practice that is rarely optimized for the families' needs.

In sum, many current ICU practices and systems influence steps of the disablement process after critical illness. However, most of this activity occurs in an information vacuum. Little high-quality evidence links specific interventions to specific aspects of survivorship. This research knowledge deficit is exacerbated by the fragmentation of post-critical illness care, ${ }^{85}$ which obstructs the ability of clinicians to receive meaningful feedback on the results of their efforts. Quality improvement systems rarely track the long-term outcomes necessary to provide closed-loop feedback. Although this lack of standardization causes pervasive deficits, it is also an opportunity to examine these diverse and independently developed programs to identify areas of particular effectiveness.

\section{Health Care Needs and Health Care Use as Outcomes of Care}

Although health care may help prevent the development of impairments, limitations, and restrictions, it is also true that impairments, limitations, and restrictions increase health care needs. The dearth of robust literature precludes a comprehensive review of the ways in which critical illnessinduced disability increases health care costs. However, there are some clear initial findings.

Survivors of critical illness have substantial and ongoing health care needs. For example, Weycker et al noted mean charges of $\$ 78,500$ (in year 2000 US\$) among patients with severe sepsis, a surprisingly large fraction of which was unrelated to the initial admission. ${ }^{104}$ Dramatic heterogeneity existed across age groups, with younger patients having 
much higher subsequent mean charges. Lee et al noted more modest costs among sepsis survivors from Alberta ICUs, with postdischarge 1 year mean costs of CAN\$20,855 (in year 2001 CAN\$, where CAN\$1 = US\$0.68). ${ }^{105}$ Importantly, this Canadian report showed a highly skewed distribution of cost. High cost outliers ( $>$ CAN $\$ 100,000$ ) were common, so estimates of the mean or of the total population burden will be quite sensitive to how these high cost outliers are detected and handled. ${ }^{106,107}$ Further, with this distribution, mean costs (although important administratively), may be poor predictors of what any individual patient will face. ${ }^{108}$ Detailed cohort analyses of acute respiratory distress syndrome (ARDS) survivors from Toronto likewise show ongoing costs. After average costs of CAN\$22,309 (2009 CAN\$) in the first year after discharge with ARDS, and CAN\$9,885 in the second, their average ongoing costs of care were CAN\$5,566 in the fifth year. But survivors with two or more comorbidities at baseline had greater costs than those with better pre-ARDS health-accruing mean total costs of almost CAN $\$ 90,000$ in 5 years. ${ }^{109,110}$

From a prognostic standpoint, these studies imply high (and heterogeneous) ongoing costs for survivors of critical illness. Unfortunately, these studies lacked rigorously described comparator arms allowing us to specify the economically relevant counterfactual (i.e., the extent to which these high costs are caused by the various critical illnesses, as opposed to the extent to which patients with poorer baseline health then become critically ill). (Possible counterfactuals include the patient's own pre-ICU costs, costs for matched patients who were hospitalized but did not require ICU care, or costs for matched patients who had some non-ICU serious illness-each of which implies a distinct scientific question that has advantages and disadvantages which should be explicitly stated.) Further, these studies have not always distinguished between the costs attributable to living as a survivor of critical illness, and the costs attributable to the increased ongoing risk of death of survivors of critical illness. ${ }^{111}$ Because health care costs spike dramatically in the months prior to death, the fact that survivors of critical illness have an increased risk of death could lead to artifactually higher costs in aggregate. In oncology, a so-called phases of disease model has been used to distinguish the costs of living with a diagnosis from the analytically distinct costs of dying after a diagnosis. ${ }^{112}$ Such work is needed in critical care as well.

Research in the area is only just beginning. There are several key deficits that need to be corrected before the full economic impact of post-critical illness disability can be assessed. First, the formal health care needs of survivors of critical illness may well be equaled by unmeasured informal care needs. Such is the case in dementia. ${ }^{89,113}$ Further, declines in function impose substantial burdens on informal caregivers. ${ }^{27,88,89,114-116}$ For example, the onset of moderate cognitive impairments is associated with families spending an additional 17.4 hours per week in informal care per patient. ${ }^{89}$ Second, none of these landmark critical care studies stratified costs by disability. The onset of disability is associated with worsened mortality ${ }^{117,118}$ and a $\$ 10,000$ increase in medical costs in the next 2 years. ${ }^{119}$ This is a particularly important problem because disability is a major driver of the crises of public health care costs and US state and federal budget deficits. In the United States, patients eligible for Medicaid by reason of disability account for only $15 \%$ of Medicaid enrollees but $43 \%$ of Medicaid expenditures. ${ }^{120}$ Third, health care use and health care needs are not synonymous. Any evaluation of health care use or needs must be careful to specify measurement approaches and attempts to determine the extent to which local system norms and availability might influence their results. ${ }^{121}$

Nonetheless, a reasonable body of evidence suggests that survivors of critical illness cost "a lot" of money. There are plausible arguments that some, perhaps much, of this cost is increased relative to appropriate comparators and may be caused by the critical illness itself. Given that the assessment of causation is incomplete for the "cost" and for the "effectiveness" of long-term outcomes for critical illness, we can offer no scientific measurement of value. Beyond these difficult questions, the implications of labeling care as "low value" or "not cost-effective" are challenging, particularly when it is difficult to identify such patients a priori. At this point in time, with so little research on the extent to which post-critical illness functional limitation, disability and quality of life might be amenable to improvements, we hesitate to use such labels.

\section{Implications}

The framework outlined here has several implications, for both practicing intensivists and researchers. Although we can make few definitive conclusions, we can offer some tentative suggestions.

\section{Toward an Approach for the Practicing Intensivist}

There are limited data upon which to build an evidence-based approach to prognosticating and preemptively managing the burdens of survivorship among our patients. Although scattered post-ICU clinics have been established, they have yet to be organized to conduct large-scale tests of randomized interventions, nor regular data sharing to allow collective learning by doing. As such, we can offer seven recommendations that are necessarily tentative, summarized in - Table $\mathbf{1}$. We, as a specialty, are at the beginning stages of learning how to optimize our care based on patients' baseline limitations and disability and their risk for worsening functional outcomes. The key message is to consider that there are multiple domains in which adverse outcomes could occur-the ICF is useful for this-and to attempt to assess and improve potential effect modifiers relevant to each particular patient.

\section{Pragmatic Suggestions to Advance Research}

Our suggestions for clinicians are necessarily hesitant given the lack of an evidence base, but we can make four recommendations for advancing research on long-term outcomes. We begin with those in which we are most confident.

First, measure outcomes over relevant time scales. Several studies have now shown that recovery after critical illness 
Table 1 Seven Tentative Recommendations for Improving Long-Term Outcomes

\begin{tabular}{l} 
1. Provide high-quality acute intensive care. This should include resuscitation and initial stabilization but also evidence-based \\
ventilator and sedation management, minimizing duration of mechanical ventilation. \\
2. Involve rehabilitation experts as early as possible in the ICU course. Such experts include physical therapists, occupational \\
therapists, social workers, physical medicine, and geriatrics. \\
3. Consider structured assessment of limitations and restrictions/disabilities. Impressionistic assessments of cognitive and physical \\
limitations have been quite poor in sensitivity and specificity, 24,125 but rapid, user-friendly systematic assessments of functional \\
limitations and disabilities are well developed, such as so-called comprehensive geriatric assessment. \\
\hline 4. Mobilize the patient's social resources and provide the patient with enabling equipment. \\
5. Arrange close follow-up, and work to avoid fragmentation of care by structured, routine hand-offs to both hospitalists and outpatient \\
providers. \\
6. Patients cannot do it by themselves: learn from PRaCTICaL.* \\
Patients sent home with instructions for physical therapy and self-reporting their progress to nurses do no better than patients \\
simply sent home; greater levels of support seem necessary, although we do not yet have proof as to the best way to provide that \\
support. \\
7. Find a way to get feedback on your patients' long-term outcomes so you can learn from them. \\
\hline
\end{tabular}

*The PRaCTICaL study of nurse led, intensive care follow-up programmes for improving long term outcomes from critical illness: a pragmatic randomised controlled trial. ${ }^{127}$

takes at least 12 to 24 months. ${ }^{110,117,122}$ Long-term outcome studies should certainly last at least 1 to 2 years and should often strive for at least 5 years of follow-up. ${ }^{123}$ Studies with shorter time scales have the onus of proving that they are demonstrating a new steady state, not simply an arbitrary point in the midst of recovery.

Second, measure and report select key social and psychological modifiers of the disablement process. Our short list of essential variables would include the following: (1) marital status, (2) social support, (3) education, (4) wealth (not just income), and (5) a measure of psychological resiliency. For brief assessments, it may be particularly valuable to use standardized question elements that allow comparability with some accepted reference standard, such as with the nationally representative, NIH-funded Health and Retirement Study (HRS). The HRS has been harmonized with an international series of ongoing studies, with carefully translated equivalent scales. Using HRS-based instruments allows easy comparability and a ready defense for why one instrument was chosen rather than another. Questionnaires are freely available at http://hrsonline.isr.umich.edu. Consistent reporting of such key variables will support hypothesis generation in the likely event of inconsistent findings across studies, particularly for smaller studies.

Third, we recommend reporting one's findings in terms of the aspects of the ICF. Studies of tissue pathology, activity limitation, restrictions in participation (i.e., disability), and quality of life are all important, but as we have argued here, they are not equivalent or interchangeable. It would take but a few words for researchers to clearly state which aspects of the ICF their outcome variables assess. Doing so makes it easier for readers to integrate findings and to draw parallels from the other fields dedicated to preventing disability and improving post-illness quality of life. Critical illness, particularly with its natural focus on adaptation and accommodation, ${ }^{18}$ may also contribute to ongoing discussions of the best way to study disability itself. ${ }^{18-20}$
Fourth, we recommend using this framework when designing randomized, controlled trials to test interventions. This recommendation implies that testing for changes in outcomes at the level of functional limitations and social disability as well as using standardized instruments for quality of life. ${ }^{1}$ We favor simple disability metrics like return to work (if appropriate), and basic and instrumental activities of daily living. Furthermore, this framework suggests that many factors outside the ICU may matter and may add variance to the outcome measurement. If an individual randomized, controlled trial cannot be powered to look for effect modification by itself, certainly it should measure the handful of key variables outlined here to allow post hoc examination for effect modification across multiple studies.

\section{Moving Forward}

The present volume of Seminars in Respiratory and Critical Care Medicine has two closely linked articles. Kress and Herridge focus on the effect of critical illness on many domains of physical disability. They have a particular interest in the current state of research on potential effect modifiers that lead to greater or lesser disability, and the usefulness of such modifiers for risk stratification and targeting of interventions. Hopkins and Girard identify the substantial cognitive and psychiatric problems under which survivors of critical illness labor. They critically and forthrightly review the level of evidence for causal linkages between critical illness and these problems and explore the interplay between the neurobiology and clinical aspects of care. The terminology of the ICF is not used in these articles, perhaps reflecting its low visibility in the ICU community. However, both articles carefully review core findings on survivorship. It is our hope that, by considering survivorship data through the prism of this disablement model, readers can more fully appreciate what is known and what needs to be investigated to better understand and intervene to attenuate disability following critical illness. 


\section{Conclusion}

A major challenge for critical care is to understand and then improve the long-term functioning, disability, and quality of life of the ever-growing group of patients surviving critical illness. Because looking at the substantial burdens of survivors may make some feel that ICU care is a waste, offering little real benefit, we face the challenge to prove our benefit for long-term, patient-centered outcomes. Furthermore, little scientific attention has been devoted to developing and assessing interventions to improve survivorship and developing systems that effectively transition from the ICU setting to several years of integrated patient-centered (evolving) follow-up. We now have a tremendous opportunity to fundamentally rethink our approach to the care of critically ill patients and to make core contributions to improving their lives.

\section{Funding}

This work was supported by NIH grants K08 HL091249 (TJI) and K12RR023250 (GN), as well as the Society of Critical Care Medicine's 2010 Vision Grant and the Claude D. Pepper Older Americans Independence Center at the University of Maryland (P30-AG028747).

\section{Disclaimer}

The views expressed in this article are those of the authors and do not necessarily reflect the position or policy of the Department of Veterans Affairs or the US government.

\section{References}

1 Spragg RG, Bernard GR, Checkley W, et al. Beyond mortality: future clinical research in acute lung injury. Am J Respir Crit Care Med 2010;181(10):1121-1127

2 World Health Organization. International Classification of Functioning, Disability and Health. Geneva, Switzerland: World Health Organization; 2001

3 Verbrugge LM, Jette AM. The disablement process. Soc Sci Med 1994;38(1):1-14

4 Freedman VA, Martin LG, Schoeni RF. Recent trends in disability and functioning among older adults in the United States: a systematic review. JAMA 2002;288(24):3137-3146

5 Iezzoni LI, Freedman VA. Turning the disability tide: the importance of definitions. JAMA 2008;299(3):332-334

6 IOM Committee on Disability in America. The Future of Disability in America. Washington, DC: National Academies Press; 2007

7 Opasich C, Pinna GD, Mazza A, et al. Six-minute walking performance in patients with moderate-to-severe heart failure; is it a useful indicator in clinical practice? Eur Heart J 2001;22(6): 488-496

8 Ingle L, Rigby AS, Nabb S, Jones PK, Clark AL, Cleland JG. Clinical determinants of poor six-minute walk test performance in patients with left ventricular systolic dysfunction and no major structural heart disease. Eur J Heart Fail 2006;8(3):321-325

9 Hertanu JS, Demopoulos JT, Yang WC, Calhoun WF, Fenigstein HA. Stroke rehabilitation: correlation and prognostic value of computerized tomography and sequential functional assessments. Arch Phys Med Rehabil 1984;65(9):505-508
10 Dodds TA, Martin DP, Stolov WC, Deyo RA. A validation of the functional independence measurement and its performance among rehabilitation inpatients. Arch Phys Med Rehabil 1993; 74(5):531-536

11 van Straten A, Reitsma JB, Limburg M, van den Bos GA, de Haan RJ. Impact of stroke type on survival and functional health. Cerebrovasc Dis 2001;12(1):27-33

12 Langhorne P, Bernhardt J, Kwakkel G. Stroke rehabilitation. Lancet 2011;377(9778):1693-1702

13 Verbrugge LM, Rennert C, Madans JH. The great efficacy of personal and equipment assistance in reducing disability. Am J Public Health 1997;87(3):384-392

14 Gold MR, Siegel JE, Russell LB, Weinstein MC, eds. CostEffectiveness in Health and Medicine. New York: Oxford University Press; 1996

15 Neumann PJ. Costing and perspective in published costeffectiveness analysis. Med Care 2009;47(7, Suppl 1):S28-S32

16 Neumann PJ. What next for QALYs? JAMA 2011;305(17): 1806-1807

17 Ubel PA. Pricing Life. Boston: MIT Press; 2000

18 Freedman VA. Adopting the ICF language for studying late-life disability: a field of dreams? J Gerontol A Biol Sci Med Sci 2009; 64(11):1172-1174, discussion 1175-1176

19 Guralnik JM, Ferrucci L. The challenge of understanding the disablement process in older persons: commentary responding to Jette AM. Toward a common language of disablement. J Gerontol A Biol Sci Med Sci 2009;64(11):1169-1171, discussion 1175-1176

20 Jette AM. Toward a common language of disablement. J Gerontol A Biol Sci Med Sci 2009;64(11):1165-1168

21 Cohen S, Doyle WJ, Skoner DP, Rabin BS, Gwaltney JM Jr. Social ties and susceptibility to the common cold. JAMA 1997;277(24): 1940-1944

22 Cooke CR, Nallamothu BK, Kahn JM, Birkmeyer JD, Iwashyna TJ. Race and timeliness of transfer for revascularization in patients with acute myocardial infarction. Med Care 2011;49(7):662-667

23 Iwashyna TJ, Christakis NA. Marriage, widowhood, and healthcare use. Soc Sci Med 2003;57(11):2137-2147

24 Smedley BD, Stith AY, Nelson AR, eds. Unequal Treatment: Confronting Racial and Ethnic Disparities in Health Care. Washington, DC: National Academies Press; 2003

25 Muni S, Engelberg RA, Treece PD, Dotolo D, Curtis JR. The influence of race/ethnicity and socioeconomic status on endof-life care in the ICU. Chest 2011;139(5):1025-1033

26 DiPietro L. Physical activity in aging: changes in patterns and their relationship to health and function. J Gerontol A Biol Sci Med Sci 2001;56(Spec No 2):13-22

27 Cameron JI, Herridge MS, Tansey CM, McAndrews MP, Cheung AM. Well-being in informal caregivers of survivors of acute respiratory distress syndrome. Crit Care Med 2006;34(1):81-86

28 Azoulay E, Pochard F, Chevret S, et al; French FAMIREA Group. Meeting the needs of intensive care unit patient families: a multicenter study. Am J Respir Crit Care Med 2001;163(1): 135-139

29 Azoulay E, Pochard F, Kentish-Barnes N, et al; FAMIREA Study Group. Risk of post-traumatic stress symptoms in family members of intensive care unit patients. Am J Respir Crit Care Med 2005;171(9):987-994

30 Holt-Lunstad J, Smith TB, Layton JB. Social relationships and mortality risk: a meta-analytic review. PLoS Med 2010;7(7): e1000316

31 Hébert R, Dubois MF, Wolfson C, Chambers L, Cohen C. Factors associated with long-term institutionalization of older people with dementia: data from the Canadian Study of Health and Aging. J Gerontol A Biol Sci Med Sci 2001;56(11):M693-M699

32 Clarke P, Ailshire JA, Lantz P. Urban built environments and trajectories of mobility disability: findings from a national 
sample of community-dwelling American adults (1986-2001). Soc Sci Med 2009;69(6):964-970

33 Formal CS, Cawley MF, Stiens SA. Spinal cord injury rehabilitation, III: Functional outcomes. Arch Phys Med Rehabil 1997; 78(3, Suppl):S59-S64

34 Francis K, Bach JR, DeLisa JA. Evaluation and rehabilitation of patients with adult motor neuron disease. Arch Phys Med Rehabil 1999;80(8):951-963

35 Gruis KL, Wren PA, Huggins JE. Amyotrophic lateral sclerosis patients' self-reported satisfaction with assistive technology. Muscle Nerve 2011;43(5):643-647

36 Clarke P, Nieuwenhuijsen ER. Environments for healthy ageing: a critical review. Maturitas 2009;64(1):14-19

37 Siebers T. Disability Theory. Ann Arbor: University of Michigan Press; 2008

38 Clarke P, Ailshire JA, Bader M, Morenoff JD, House JS. Mobility disability and the urban built environment. Am J Epidemiol 2008;168(5):506-513

39 Clarke PJ, Ailshire JA, Nieuwenhuijsen ER, de Kleijn-de Vrankrijker MW. Participation among adults with disability: the role of the urban environment. Soc Sci Med 2011;72(10):1674-1684

40 Freedman VA, Grafova IB, Schoeni RF, Rogowski J. Neighborhoods and disability in later life. Soc Sci Med 2008;66(11):2253-2267

41 Ubel PA. You're Stronger Than You Think: Tapping into the Secrets of Emotionally Resilient People. New York: McGraw-Hill; 2006

42 Smith DM, Loewenstein G, Jankovic A, Ubel PA. Happily hopeless: adaptation to a permanent, but not to a temporary, disability. Health Psychol 2009;28(6):787-791

43 Baron J, Asch DA, Fagerlin A, et al. Effect of assessment method on the discrepancy between judgments of health disorders people have and do not have: a web study. Med Decis Making 2003; 23(5):422-434

44 Ubel PA, Loewenstein G, Jepson C. Whose quality of life? A commentary exploring discrepancies between health state evaluations of patients and the general public. Qual Life Res 2003; 12(6):599-607

45 Van Houtven G, Powers J, Jessup A, Yang JC. Valuing avoided morbidity using meta-regression analysis: what can health status measures and QALYs tell us about WTP? Health Econ 2006; 15(8):775-795

46 Cheng DC, Karski J, Peniston C, et al. Early tracheal extubation after coronary artery bypass graft surgery reduces costs and improves resource use: a prospective, randomized, controlled trial. Anesthesiology 1996;85(6):1300-1310

47 Jucá R, Monte L. Early tracheal extubation after coronary artery bypass grafting. J Thorac Cardiovasc Surg 1997;114(4):687-688

48 Neelakanta G, Sopher M, Chan S, et al. Early tracheal extubation after liver transplantation. J Cardiothorac Vasc Anesth 1997; 11(2):165-167

49 Sato M, Suenaga E, Koga S, Matsuyama S, Kawasaki H, Maki F. Early tracheal extubation after on-pump coronary artery bypass grafting. Ann Thorac Cardiovasc Surg 2009;15(4):239-242

50 Cray SH, Holtby HM, Kartha VM, Cox PN, Roy WL. Early tracheal extubation after paediatric cardiac surgery: the use of propofol to supplement low-dose opioid anaesthesia. Paediatr Anaesth 2001;11(4):465-471

51 Augoustides JG, Watcha SM, Pochettino A, Jobes DR. Early tracheal extubation in adults undergoing single-lung transplantation for chronic obstructive pulmonary disease: pilot evaluation of perioperative outcome. Interact Cardiovasc Thorac Surg 2008; 7(5):755-758

52 Bernhardt J, Dewey H, Thrift A, Collier J, Donnan G. A very early rehabilitation trial for stroke (AVERT): phase II safety and feasibility. Stroke 2008;39(2):390-396

$53 \mathrm{Hu}$ MH, Hsu SS, Yip PK, Jeng JS, Wang YH. Early and intensive rehabilitation predicts good functional outcomes in patients admitted to the stroke intensive care unit. Disabil Rehabil 2010;32(15):1251-1259
54 Cumming TB, Collier J, Thrift AG, Bernhardt J. The effect of very early mobilisation after stroke on psychological well-being. J Rehabil Med 2008;40(8):609-614

55 Hopkins RO, Spuhler VJ, Thomsen GE. Transforming ICU culture to facilitate early mobility. Crit Care Clin 2007;23(1):81-96

56 Morris PE, Goad A, Thompson C, et al. Early intensive care unit mobility therapy in the treatment of acute respiratory failure. Crit Care Med 2008;36(8):2238-2243

57 Needham DM. Mobilizing patients in the intensive care unit: improving neuromuscular weakness and physical function. JAMA 2008;300(14):1685-1690

58 Schweickert WD, Pohlman MC, Pohlman AS, et al. Early physical and occupational therapy in mechanically ventilated, critically ill patients: a randomised controlled trial. Lancet 2009;373(9678): 1874-1882

59 Pronovost PJ, Needham DM, Berenholtz SM, et al. An intervention to decrease catheter-related bloodstream infections in the ICU. N Engl J Med 2006;355(26):2725-2732

60 Saint S, Olmsted RN, Fakih MG, et al. Translating health careassociated urinary tract infection prevention research into practice via the bladder bundle. Jt Comm J Qual Patient Saf 2009; 35(9):449-455

61 Saint S, Savel RH, Matthay MA. Enhancing the safety of critically ill patients by reducing urinary and central venous catheterrelated infections. Am J Respir Crit Care Med 2002;165(11): 1475-1479

62 Li G, Malinchoc M, Cartin-Ceba R, et al. Eight-year trend of acute respiratory distress syndrome: a population-based study in Olmsted County, Minnesota. Am J Respir Crit Care Med 2011; 183(1):59-66

63 Girard TD, Kress JP, Fuchs BD, et al. Efficacy and safety of a paired sedation and ventilator weaning protocol for mechanically ventilated patients in intensive care (Awakening and Breathing Controlled trial): a randomised controlled trial. Lancet 2008; 371(9607):126-134

64 Clermont G, Kong L, Weissfeld LA, et al; NHLBI ARDS Clinical Trials Network. The effect of pulmonary artery catheter use on costs and long-term outcomes of acute lung injury. PLoS ONE 2011; 6(7):e22512

65 Mikkelsen ME, Lanken PE, Biester R, et al. Conservative fluid strategy is associated with neurocognitive deficits in survivors of acute lung injury. Paper presented at: American Thoracic Society; May 21, 2008; Toronto, Ontario. PMID: 22492988

66 Angus DC. The lingering consequences of sepsis: a hidden public health disaster? JAMA 2010;304(16):1833-1834

67 Suffredini AF, Munford RS. Novel therapies for septic shock over the past 4 decades. JAMA 2011;306(2):194-199

68 Inouye SK, Brown CJ, Tinetti ME. Medicare nonpayment, hospital falls, and unintended consequences. N Engl J Med 2009;360(23): 2390-2393

69 Hodgin KE, Nordon-Craft A, McFann KK, Mealer ML, Moss M. Physical therapy utilization in intensive care units: results from a national survey. Crit Care Med 2009;37(2):561-566, quiz 566-568

70 Kalisch BJ. Missed nursing care: a qualitative study. J Nurs Care Qual 2006;21(4):306-313, quiz 314-315

71 Kalisch BJ, Landstrom G, Williams RA. Missed nursing care: errors of omission. Nurs Outlook 2009;57(1):3-9

72 Jackson JC, Ely EW, Morey MC, et al. Cognitive and physical rehabilitation of intensive care unit survivors: results of the RETURN randomized controlled pilot investigation. Crit Care Med 2012;40(4):1088-1097

73 Cicerone KD, Dahlberg C, Kalmar K, et al. Evidence-based cognitive rehabilitation: recommendations for clinical practice. Arch Phys Med Rehabil 2000;81(12):1596-1615

74 Cicerone KD, Dahlberg C, Malec JF, et al. Evidence-based cognitive rehabilitation: updated review of the literature from 1998 through 2002. Arch Phys Med Rehabil 2005;86(8):1681-1692 
75 Cicerone KD, Langenbahn DM, Braden C, et al. Evidence-based cognitive rehabilitation: updated review of the literature from 2003 through 2008. Arch Phys Med Rehabil 2011;92(4):519-530

76 Kress JP, Pohlman AS, O'Connor MF, Hall JB. Daily interruption of sedative infusions in critically ill patients undergoing mechanical ventilation. N Engl J Med 2000;342(20):1471-1477

77 Kho ME, Al Damluji A, Zanni JM, Needham DM. Feasibility and safety of novel use of interactive videogames for physical rehabilitation in the intensive care unit [abstract]. Am J Respir Crit Care Med 2011;183:A4124

78 Kho ME, Damluji A, Zanni JM, Needham DM. Feasibility and observed safety of interactive video games for physical rehabilitation in the intensive care unit: a case series. J Crit Care 2012; 27(2):219, e1-e6

79 Ely EW, Shintani A, Truman B, et al. Delirium as a predictor of mortality in mechanically ventilated patients in the intensive care unit. JAMA 2004;291(14):1753-1762

80 Girard TD, Jackson JC, Pandharipande PP, et al. Delirium as a predictor of long-term cognitive impairment in survivors of critical illness. Crit Care Med 2010;38(7):1513-1520

81 Pisani MA, Kong SY, Kasl SV, Murphy TE, Araujo KL, Van Ness PH. Days of delirium are associated with 1-year mortality in an older intensive care unit population. Am J Respir Crit Care Med 2009;180(11):1092-1097

82 The Acute Respiratory Distress Syndrome Network. Ventilation with lower tidal volumes as compared with traditional tidal volumes for acute lung injury and the acute respiratory distress syndrome. N Engl J Med 2000;342(18):1301-1308

83 Murphy SL. Geriatric research. Am J Occup Ther 2010;64(1): 172-181

84 Murphy SL. Update on geriatric research in productive aging. Am J Occup Ther 2011;65(2):197-206

85 Unroe M, Kahn JM, Carson SS, et al. One-year trajectories of care and resource utilization for recipients of prolonged mechanical ventilation: a cohort study. Ann Intern Med 2010;153(3): 167-175

86 Cameron JI, Herridge MS, Tansey CM, McAndrews MP, Cheung AM. Well-being in informal caregivers of survivors of acute respiratory distress syndrome. Crit Care Med 2006;34(1):81-86

87 Hayman JA, Langa KM, Kabeto MU, et al. Estimating the cost of informal caregiving for elderly patients with cancer. J Clin Oncol 2001;19(13):3219-3225

88 Hickenbottom SL, Fendrick AM, Kutcher JS, Kabeto MU, Katz SJ, Langa KM. A national study of the quantity and cost of informal caregiving for the elderly with stroke. Neurology 2002;58(12): 1754-1759

89 Langa KM, Chernew ME, Kabeto MU, et al. National estimates of the quantity and cost of informal caregiving for the elderly with dementia. J Gen Intern Med 2001;16(11):770-778

90 Langa KM, Fendrick AM, Flaherty KR, Martinez FJ, Kabeto MU, Saint S. Informal caregiving for chronic lung disease among older Americans. Chest 2002;122(6):2197-2203

91 Langa KM, Fultz NH, Saint S, Kabeto MU, Herzog AR. Informal caregiving time and costs for urinary incontinence in older individuals in the United States. J Am Geriatr Soc 2002;50(4): 733-737

92 Langa KM, Valenstein MA, Fendrick AM, Kabeto MU, Vijan S. Extent and cost of informal caregiving for older Americans with symptoms of depression. Am J Psychiatry 2004;161(5):857-863

93 Langa KM, Vijan S, Hayward RA, et al. Informal caregiving for diabetes and diabetic complications among elderly americans. J Gerontol B Psychol Sci Soc Sci 2002;57(3):S177-S186

94 Gure TR, Kabeto MU, Blaum CS, Langa KM. Degree of disability and patterns of caregiving among older Americans with congestive heart failure. J Gen Intern Med 2008;23(1):70-76

95 Fumis RR, Deheinzelin D. Family members of critically ill cancer patients: assessing the symptoms of anxiety and depression. Intensive Care Med 2009;35(5):899-902
96 Delva D, Vanoost S, Bijttebier P, Lauwers P, Wilmer A. Needs and feelings of anxiety of relatives of patients hospitalized in intensive care units: implications for social work. Soc Work Health Care 2002;35(4):21-40

97 Anderson WG, Arnold RM, Angus DC, Bryce CL. Passive decisionmaking preference is associated with anxiety and depression in relatives of patients in the intensive care unit. J Crit Care 2009; 24(2):249-254

98 Anderson WG, Arnold RM, Angus DC, Bryce CL. Posttraumatic stress and complicated grief in family members of patients in the intensive care unit. J Gen Intern Med 2008;23(11):1871-1876

99 Chui WY, Chan SW. Stress and coping of Hong Kong Chinese family members during a critical illness. J Clin Nurs 2007;16(2): 372-381

100 Pochard F, Darmon M, Fassier T, et al; French FAMIREA study group. Symptoms of anxiety and depression in family members of intensive care unit patients before discharge or death: a prospective multicenter study. J Crit Care 2005;20(1):90-96

101 Sullivan DR, Liu X, Titus J, Pate DA, Ismail DM, Netzer G. Learned helplessness and perceived stress among families of patients admitted to medical, surgical and trauma intensive care units [abstract]. Am J Respir Crit Care Med 2011;183:A1455

102 Van Pelt DC, Milbrandt EB, Qin L, et al. Informal caregiver burden among survivors of prolonged mechanical ventilation. Am J Respir Crit Care Med 2007;175(2):167-173

103 Van Pelt DC, Schulz R, Chelluri L, Pinsky MR. Patient-specific, time-varying predictors of post-ICU informal caregiver burden: the caregiver outcomes after ICU discharge project. Chest 2010; 137(1):88-94

104 Weycker D, Akhras KS, Edelsberg J, Angus DC, Oster G. Long-term mortality and medical care charges in patients with severe sepsis. Crit Care Med 2003;31(9):2316-2323

105 Lee H, Doig CJ, Ghali WA, Donaldson C, Johnson D, Manns B. Detailed cost analysis of care for survivors of severe sepsis. Crit Care Med 2004;32(4):981-985

106 Basu A, Manning WG. Issues for the next generation of health care cost analyses. Med Care 2009;47(7, Suppl 1):S109-S114

107 Van Houtven $\mathrm{CH}$, Norton EC. Informal care and Medicare expenditures: testing for heterogeneous treatment effects. J Health Econ 2008;27(1):134-156

108 Manning WG. The logged dependent variable, heteroscedasticity, and the retransformation problem. J Health Econ 1998;17(3): 283-295

109 Cheung AM, Tansey CM, Tomlinson G, et al. Two-year outcomes, health care use, and costs of survivors of acute respiratory distress syndrome. Am J Respir Crit Care Med 2006;174(5):538-544

110 Herridge MS, Tansey CM, Matté A, et al; Canadian Critical Care Trials Group. Functional disability 5 years after acute respiratory distress syndrome. N Engl J Med 2011;364(14):1293-1304

111 Quartin AA, Schein RMH, Kett DH, Peduzzi PN; Department of Veterans Affairs Systemic Sepsis Cooperative Studies Group. Magnitude and duration of the effect of sepsis on survival. JAMA 1997;277(13):1058-1063

112 Yabroff KR, Lamont EB, Mariotto A, et al. Cost of care for elderly cancer patients in the United States. J Natl Cancer Inst 2008; 100(9):630-641

113 Ernst RL, Hay JW. Economic research on Alzheimer disease: a review of the literature. Alzheimer Dis Assoc Disord 1997; 11(Suppl 6):135-145

114 Douglas SL, Daly BJ. Caregivers of long-term ventilator patients: physical and psychological outcomes. Chest 2003;123(4): 1073-1081

115 Schulz R, Beach SR. Caregiving as a risk factor for mortality: the Caregiver Health Effects Study. JAMA 1999;282(23):2215-2219

116 Covinsky KE, Goldman L, Cook EF, et al; SUPPORT Investigators. Study to Understand Prognoses and Preferences for Outcomes and Risks of Treatment. The impact of serious illness on patients' families. JAMA 1994;272(23):1839-1844 
117 Boyd CM, Landefeld CS, Counsell SR, et al. Recovery of activities of daily living in older adults after hospitalization for acute medical illness. J Am Geriatr Soc 2008;56(12):2171-2179

118 Boyd CM, Xue QL, Guralnik JM, Fried LP. Hospitalization and development of dependence in activities of daily living in a cohort of disabled older women: the Women's Health and Aging Study I. J Gerontol A Biol Sci Med Sci 2005;60(7):888-893

119 Fried TR, Bradley EH, Williams CS, Tinetti ME. Functional disability and health care expenditures for older persons. Arch Intern Med 2001;161(21):2602-2607

120 Kaiser Family Foundation. Medicaid Enrollees and Expenditures by Enrollment Group. 2006. Kaiser Fast Facts, Source: Kaiser Commission on Medicaid and the Uninsured and Urban Institute estimates based on 2006 MSIS data. http://factskfforg/chartaspx? $\mathrm{ch}=465$ 2009. Accessed November 19, 2009

121 Wennberg JE, Cooper MM, eds. The Dartmouth Atlas of Health Care. Chicago, IL: American Hospital Publishing; 1998

122 Sacanella E, Pérez-Castejón JM, Nicolás JM, et al. Functional status and quality of life 12 months after discharge from a medical ICU in healthy elderly patients: a prospective observational study. Crit Care 2011;15(2):R105

123 Iwashyna TJ. Survivorship will be the defining challenge of critical care in the 21st century. Ann Intern Med 2010;153(3): 204-205

124 Bradford A, Kunik ME, Schulz P, Williams SP, Singh H. Missed and delayed diagnosis of dementia in primary care: prevalence and contributing factors. Alzheimer Dis Assoc Disord 2009;23(4): 306-314

125 Calkins DR, Rubenstein LV, Cleary PD, et al. Failure of physicians to recognize functional disability in ambulatory patients. Ann Intern Med 1991;114(6):451-454

126 Hazzard WR, Halter JB, Ouslander JG. Hazzard's Geriatric Medicine and Gerontology. New York: McGraw-Hill Medical; 2009

127 Cuthbertson BH, Rattray J, Campbell MK, et al; PRaCTICaL study group. The PRaCTICaL study of nurse led, intensive care follow-up programmes for improving long term outcomes from critical illness: a pragmatic randomised controlled trial. BMJ 2009; 339:b3723 